\title{
Return traction current system's operation in cold climate regions
}

\author{
Svetlana Makasheva ${ }^{1, *}$ and Pavel Pinchukov ${ }^{1}$ \\ ${ }^{1}$ Far Eastern State Transport University, Seryshev st. 47, 680021, Khabarovsk, Russia
}

\begin{abstract}
The paper deals the problem of the reverse traction current's asymmetry at the AC electrified railways. The features of return traction current system's operation under conditions of cold climate are considered. The goal of work is to determinate value of return traction current asymmetry coefficient for cold climate regions operating AC electrified railways. To achieve the goal the methods of scientific analysis, imitation modelling, experimental study are used. Types and rationing of return traction current asymmetry are accented. The return traction current system model is created in Multisim 12.0 software for analyse the degree of various factors influence on the return traction current's asymmetry. Main influencing factors for asymmetry coefficient in cold climate regions as a traction current value and catenary tower resistance are considered. The calculated graphic dependences of the asymmetry coefficient as a function of the traction current and the catenary tower resistance are given. Algorithm for identifying the critical zones (hazardous areas) by graphical dependencies and predicting the system's predicament states is described.
\end{abstract}

\section{Introduction}

All transport services are dependent upon the atmosphere, weather and climate. The weather determines the success of daily operations and can cause significant delays at all times of year due to extremes of temperature, precipitation, wind and humidity. The climate should determine the strategic design of track and rolling stock to cope with the extremes of weather. Despite the fact that it is often thought that the railways are the least weather sensitive, the atmosphere can take significant acts a hazard to transport activities $[1,2]$.

The AC electrified railways infrastructure is designed so that the traction current from contact wire through locomotives should go by the running rails to traction substation, but occasionally the ground acts as a conductor, transmitting current to areas that are distant from the rail $[2,3]$. This circuit in traction power supply system is called as a return or reverse traction current system and plays very important role in functioning of railways signals and interlocking system and also in railways power supply system [2,4]. The return traction current system plays the most important role in ensuring traffic safety and road carrying capacity because its elements are transmitters for signal current of centralized control blocking (CCB) and also automatic train control (ATC) devices.

\footnotetext{
*Corresponding author: jap_svet@mail.ru
} 
In the same time, return traction current system's elements are a continuous line for passing traction currents back to traction substation. The share of failures due to malfunction of the reverse traction circuit is still high up to $50 \%$ of all the faults of the railways signals and interlocking and ATC devices [5,6]. Other words return traction current system is responsible for a significant number of faults in the railway infrastructure system. Consequently reducing the number of faults by improving the conditions for return traction current system's operation is an urgent task.

Reverse traction current entering through the wheelset to the running rails divides into two flows for each of rails. However, an unequal separation of this current occurs between the rails for a variety of reasons. The inequality of return currents, that flows in adjacent rails, is called as return traction current asymmetry. The over-standard asymmetry is usually called as a cause of various types of faults in the signals, interlocking and ATC devices, including the rail circuits, dangerous failures of technical means, expressed in the track relay false operation, the false employment of the block section, which eventually leads to train traffic interrupting $[2,4,7-10]$.

It is well known that the return traction current's asymmetry depends on the meteorological conditions, ground conditions and is significantly strengthened in the cold season especially in cold climate regions. Return traction current asymmetry reaches its maximum value usually in winter due to the frozen soils high resistance $[2,7,11]$.

Thus, the aim of the work is to analyse return traction current system's operation conditions in cold climate order to identify the main negative factors that impede the operation of reverse current circuits and enhance its asymmetry. The revealed features will help to develop measures to reduce return traction current asymmetry and, as a consequence, reduce the number of failures of ATC and signaling and telecommunications technical means and improve TC immunity for safe railway operation.

\section{Types and rationing of return traction current asymmetry}

The principal scheme of traction and signaling currents flow in the double-rail track circuit with butting connectors and throttle transformers is shown at Figure 1.

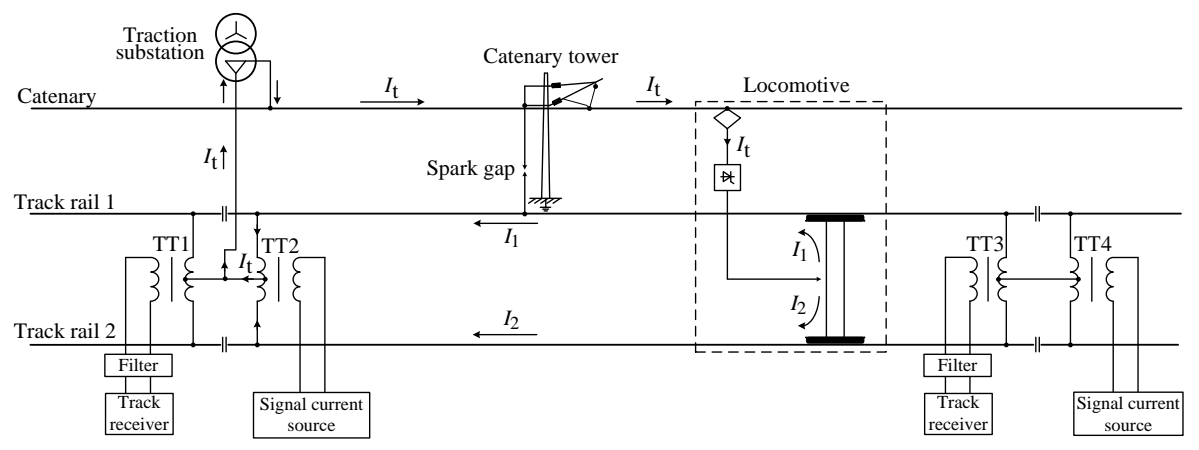

Fig. 1. The scheme of traction and signaling currents flow.

As it shown at figure 1, the return traction current $I_{\mathrm{t}}$ comes from the catenary to the locomotive leaves it through the wheel pair and divides into two parts: $I_{1}$ and $I_{2}$. These reverse traction currents flow through the first and second rails respectively. Because of many random factors the currents $I_{1}$ and $I_{2}$ are not equal $[4,5,12,13]$.

According to [14] the relative value of the return traction current asymmetry is characterized by the asymmetry coefficient $K_{\mathrm{A}}$ and is calculated by equation 


$$
K_{A}=\frac{\left|I_{1}-I_{2}\right|}{I_{1}+I_{2}} \cdot 100 \%
$$

According to [14] the maximum permissible value of asymmetry coefficient $K_{\mathrm{A}}$ should not exceed $4 \%$ in AC electric traction system with double-rail track circuits.

There are two types of return traction current asymmetry: the longitudinal and the transverse asymmetry. Both types bring into existence the interference at the input of receiving devices of the track circuits and automatic train control system [2, 4, 5, 8, 12-14].

The value of asymmetry coefficient $K_{\mathrm{A}}$ depends on three main factors [4, 7, 8, 14]:

1.resistance to the traction current of each rail thread (renders influence on the longitudinal asymmetry);

2.the resistance of each rail thread in relation to the ground and connected to rails devices (renders influence on the transverse asymmetry);

3. value of reverse traction current (number of electrically locomotives on the traction section) - refers to both types of return traction current asymmetry.

Thus, the standardization of asymmetry coefficient is made as a result of both types longitudinal and the transverse asymmetry. But to develop measures to reduce asymmetry and evaluate the influencing factors especially in cold climate regions, it is important to consider every type of asymmetry separately and more detail.

\subsection{Longitudinal asymmetry}

Longitudinal asymmetry is caused by different rail resistance to traction current, and is determined mainly by the state of butting connectors $[2,4,5,12]$. But this resistance can be increased several times due to a number of circumstances (breakage, metal corrosion, weakening the tightening of bolts). In addition such faulty joints can be several in one blocksection that considerably aggravates the situation.

Longitudinal asymmetry in the track circuits can also occur because of differences in resistance of the short and long choke cables or because of the increased transient resistance in the fixturing point of the connector with the rail. It is possible to reduce the resistance of the long choke cable by replacing the connector with a large cross section or to use the connector of equal length.

This type of asymmetry is weakly dependents on temperature changes. As for a cold climate, the changes in the calculation of the asymmetry coefficient $K_{\mathrm{A}}$ compared to normal region are weak or virtually invisible.

\subsection{Transverse asymmetry}

Transverse asymmetry depends on the difference of the resistances of the insulation of rails relative to the ground. This type of asymmetry is a consequence of the conductive earth connection to the rails of the catenary supports, signal posts, bridges and other metal structures, located close to the tracks $[2,4,5,11-13,15]$.

The resistance of the insulation of the rail threads relative to the ground depends on the meteorological conditions, the construction of the top, the structure of the path, its obstruction. In cold climate regions with the negative temperatures and frozen ballast, resistance of the rail line insulation increases $[11,13,16,17]$. The greatest difference in the resistance of insulation of rail threads to the ground reaches in winter. Due to the high resistance of the frozen ground, the conductivity between one rails ground and between the rails is practically equal zero. The conductivity of the insulation of the other rail relative to the ground is determined by the conductivity of the supports of the contact network and can be significant. 


\section{Return traction current system's modelling}

To analyze the degree of various factors influence on the reverse traction current's asymmetry the simulation model of AC electrified railways return traction circuit is implemented in Multisim 12.0 software. The simulation model based on the real data of the research object at Far East of Russia and at figure 2.

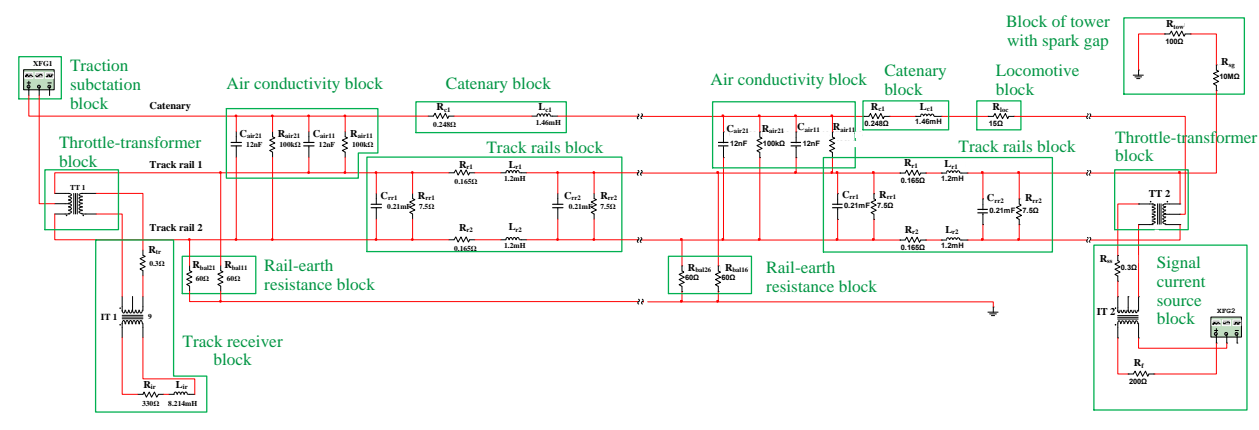

Fig. 2. Simulation model of the return traction circuit.

For each block, shown at figure 2, it was necessary to determine the resistance values of elements from the reference data and then set them in model. Taking into account the system operation in a cold climate, resistances were chosen precisely for the region temperature range $[11,13,16,17]$. In the cold weather conditions the frozen ground resistance is very high and the leakage currents are excluded. Therefore it is possible to assume that all the traction current enters the circuit without leakage to the ground.

As an example, for track rail block it is well-known, that the rail resistance and reactance depend on the current magnitude, flowing through it. According to [11], for flowing current of $625 \mathrm{~A}$ and frequency $50 \mathrm{~Hz}$ the resistance of P65 track rail type is equal $\mathrm{R}_{r}=0.11 \mathrm{Ohm} / \mathrm{km}$. Thus, for $1.5 \mathrm{~km}$ block-section track rail length model $\mathrm{R}_{r}=0.11 \cdot 1.5=0.165 \mathrm{Ohm}$. Similarly, other blocks are modeled.

Sleepers and ballast largely change their electrical conductivity, depending on the presence of moisture in them, changes in ambient temperature and other factors. Therefore, the insulation resistance of the rail circuit, or, as it is usually called, the ballast resistance, varies over a wide range (from 0.25 to $100 \mathrm{Ohm} \cdot \mathrm{km}$ ) and in practice is very unstable [11, 12, 15].

Operating experience $[11,12]$ has shown that for cold climate regions the resistance varies in the range:

-with a dry, slightly frozen ballast $-50 \mathrm{Ohm} \cdot \mathrm{km}$;

- with a heavily frozen ballast $-100 \mathrm{Ohm} \cdot \mathrm{km}$.

Rail circuit is the distributed parameter circuit and it characterized by a multitude of states for normal, emergency and post-emergency modes $[4,8,11,13]$. Thus, in order to take into account the resistances along the entire length of the rail circuits is duplicated the track rail block and the catenary block four times between the track receiver block and signal current source block. At figure 2 it is shown twice, and the rest of it is replaced by the rupture of mentioned circuits.

In model are used the following symbols shown at figure $2: R_{c 1}$ - catenary reactance; $R_{l o c}$ -locomotive reactance; $L_{r 1}, L_{r 2}$ - inductive reactance of first (1) and second (2) rails, respectively; $R_{s g}$ - spark gap reactance; $R_{\text {air }}$ - air reactance; $R_{\text {tow }}$ - tower reactance; $R_{b a l}$ track ballast layer reactance; $R_{r r 12}$ - reactance between first and second rails, etc. 
The simulation model adequacy was verified by the condition of equality of voltages and currents measured at the track relay terminals in signal current source block. It was measured twice: in the model and at the real object during experimental measurement. Comparison of the results of both cases showed that the condition of the permissible engineering error is satisfied. Relative error value is less than 5\% that allows ascertaining the constructed model correctness.

\section{Results of asymmetry coefficient calculating}

As described above, the magnitude of the traction current significantly affects the asymmetry in the return current circuit. Therefore, at the first stage of calculations, the maximum value of traction current was determined. This maximum current locomotive consumes at the estimated (maximum) gradient while the rail block section crossing. As an example, the values of the traction currents and train weight for the object of study located at the Far Eastern Railway of Russia are shown in table 1.

Table 1. Train weight and maximum traction current.

\begin{tabular}{|c|c|}
\hline Train weight, tons & Traction current, $\mathrm{I}$, ampere \\
\hline 12000 & 1020 \\
\hline 10000 & 980 \\
\hline 9000 & 970 \\
\hline 6000 & 850 \\
\hline 3000 & 520 \\
\hline
\end{tabular}

At the second stage of calculations, the locomotive resistance, corresponding to the calculated traction current magnitude is put in the model. Further, the rail resistance $\mathrm{R}_{r}$ which corresponds to the mentioned flowing current, was established. Then the currents in every rail $\mathrm{I}_{1}$ and $\mathrm{I}_{2}$ were measured by multimeter in model. Further, the asymmetry coefficient $K_{\mathrm{A}}$ was calculated by equation (1).

During the calculations, it was determined that when the ballast resistance varies from 50 to $100 \mathrm{Ohm} \cdot \mathrm{km}$, the total ground-to-rail resistance changes. However, the currents in the first and second rails vary proportionally, without having a difference between themselves. Therefore, the asymmetry coefficient does not change.

The essential influence on the asymmetry coefficient is the resistance of every rail and the resistance of the tower. However, since the catenary tower is attached to only one of the two rails, its resistance exerts the strongest (prevailing) influence on the asymmetry coefficient. As a calculations result the graphic dependencies of asymmetry coefficient $K_{\mathrm{A}}$ were constructed as it shown at figure 3.

Color oblique lines in figure 3 shows the dependence of the asymmetry coefficient $K_{\mathrm{A}}$ on the traction current $I_{\mathrm{t}}$ and the contact network's tower resistance $R_{\text {tower }}$ as function $K_{\mathrm{A}}=\mathrm{f}\left(I_{\mathrm{t}}\right.$ $\left.; R_{\text {tower }}\right)$. The red horizontal line at figure 3 shows the $4 \%$ permissible value of the asymmetry coefficient called at figure 3 as asymmetry coefficient limit. At the points of $4 \%$ level intersection with graphical dependencies for a given value of current $K_{\mathrm{A}}=\mathrm{f}\left(I_{\mathrm{t}} ; R_{\text {tower }}\right)$, a perpendicular to the x-axis (axis of contact network's tower resistance $R_{\text {tower }}$ ) is omitted. This path is shown by arrows of the same color as the color of the dependence $K_{\mathrm{A}}=\mathrm{f}\left(I_{\mathrm{t}} ; R_{\text {tower }}\right)$. The intersection of the arrow with the axis $R_{\text {tower }}$ gives the values of the critical resistance of contact network's tower (shown in the same color as the arrow and the dependence $K_{\mathrm{A}}=\mathrm{f}\left(I_{\mathrm{t}} ; R_{\text {tower }}\right)$. 


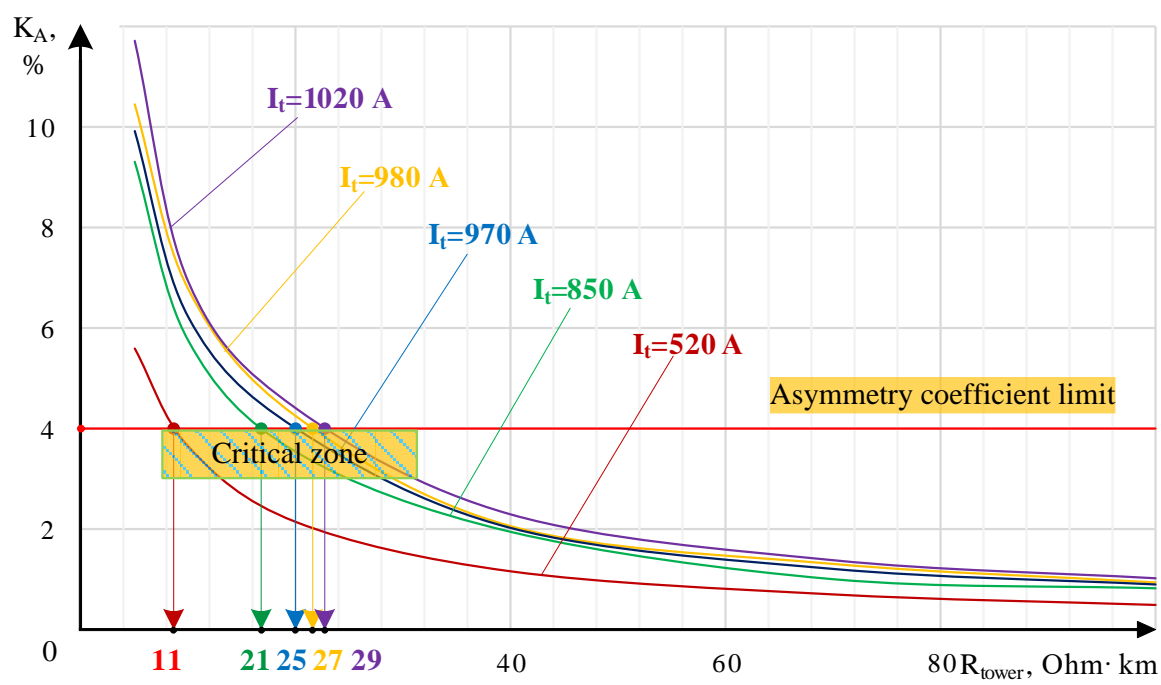

Fig. 3. Results of asymmetry coefficient calculating.

For example, for red color oblique line in figure 3 and traction current $I_{\mathrm{t}}=520$ ampere, the red horizontal line of $4 \%$ permissible value of the asymmetry coefficient across the graphical dependencies $K_{\mathrm{A}}=\mathrm{f}\left(I_{\mathrm{t}} ; R_{\text {tower }}\right)$. The point of their intersection is shown in red. From this point the red line on the x-axis is omitted, which corresponds to the contact network's tower resistance value $R_{\text {tower }}=11 \mathrm{Ohm} \cdot \mathrm{km}$.

Similarly for violet dots and lines at figure 3: for traction current $I_{\mathrm{t}}=1020$ A the contact network's tower resistance value is $R_{\text {tower }}=29 \mathrm{Ohm} \cdot \mathrm{km}$. Following this route, as shown at figure 3, the critical zone or pre-failure zone for operation of ATC, signaling and telecommunications technical systems devices, was calculated and determinated for object under researching, located at the Far Eastern Railway of Russia.

\section{Discussion}

Following the presented algorithm, two basic parameters of traction power supply system were revealed. There are traction current $I_{\mathrm{t}}$ and contact network's tower resistance value $R_{\text {tower }}$. These two parameters significantly affect the return traction current's asymmetry asymmetry coefficient.

Thus, for each railway zone it is possible to determine the critical contact network's tower resistance value $R_{\text {tower }}$ depending on the range of locomotive currents. Other words, the critical pre-failure zone for operation of ATC, signaling and telecommunications technical systems devices, can be calculated and determinated for any railways object, as shown at figure 3. For example, where are no risk of asymmetry coefficient exceeding $3 \%$ and more, with tower resistance value upper $30 \mathrm{Ohm} \cdot \mathrm{km}$ for any values of traction currents from 500 to 1000 ampere at object under researching, located at the Far Eastern Railway of Russia. But if the resistance drops below $29 \mathrm{Ohm} \cdot \mathrm{km}$, there is a risk of asymmetry coefficient up to $4 \%$, i.e. there is a critical (danger) zone.

Suchwise, the created imitation model allows to take into account the features of cold climate, calculate and determinate the fre-failure conditions of ATC, signaling and telecommunications technical systems devices by determining the critical values of the return traction current system's asymmetry coefficient. 
Timely identification of such zones allows timely measures to improve the situation. For example, if the contact network's tower resistance is lower than the detected critical point, it is advisable to apply measures to increase this resistance up to the tower replacement. Thus, it is necessary to control the value of the contact network's tower resistance and not to exceed the values recommended by the calculation results in those zones, where there are increased locomotive currents.

The model parameters can be adapted for any section of the railway where there is a return traction current asymmetry problem is present. As we can see from figure 3 , in order to avoid failures of ATC, signaling and telecommunications technical systems devices during heavy haul traffic in cold climate regions at research object where the locomotive traction current reaches 1000 ampere and higher, the contact network's tower resistance should not be less than $30 \mathrm{Ohm} \cdot \mathrm{km}$. Also, in areas with traction currents from 900 to 1000 ampere it should not be less than $35 \mathrm{Ohm} \cdot \mathrm{km}$. Otherwise, the allowable asymmetry coefficient may be exceeded, which would entail failures of ATC and signaling and telecommunications technical means and decrease TC immunity.

\section{Conclusion}

Obtained results leads to the following conclusions:

1. The main feature of the return current circuit operation in a cold climate regions is the high resistance of the rail track ballast layer (about $50 \div 100 \mathrm{Ohm} \cdot \mathrm{km}$ ), which prevents the leaking currents from rails into the ground.

2. Created simulation model allows analyze influence of many various factors on the asymmetry coefficient of the return current system for AC power traction network such as: temperature and humidity, power and type of throttle-transformers, rail track ballast resistance, catenary tower resistance, type of spark gap, etc.;

3. The model allows to take into account the traction currents and to calculate and predict the status before return current circuit failure proceeding from the maximum normed value of the asymmetry coefficient.

4. Positive effect on reducing asymmetry of the return current system for AC power traction network can be achieved by increase and maintain a high level of catenary tower resistance.

\section{References}

1. I. Oslakovic, H. ter Maat, A. Hartmann, G. Dewulf, Procedia - Social and Behavioral Sciences 48 (2012)

2. E. Ter-Oganov, A. Pyshkin, Railway electrification system (2014)

3. A. Morant, A. Wisten, D. Galar, U. Kumar, S. Niska, Electromagnetic Compatibility (EMC EUROPE) Int. Symp., 1-7 (2012)

4. V. Shamanov, Russian Electrical Engineering 85(8), 509 (2014)

5. S. Loginov, Transzhat 11, (2012)

6. P. Pinchukov, Russ. Electr. Engin. 87, 62 (2016)

7. E. Bastin, S. Makasheva, Postulat 5 (2018)

8. G. Theeg, S. Vlasenko, Railway Signaling \& Interlocking: Int. Compendium (2017)

9. P. Pinchukov, J. of Traction and Rolling Stock Institute of FESTU 12, 108-110 (2016)

10. S. Makasheva, Russ. Electr. Engin. 87, 107 (2016)

11. A. Kirilenko, N. Pelmeneva, Electric track circuits (2006) 
12. L. Kloow, High-speed train operation in winter climate (2011)

13. K. Menaker, E. Bushuev Automation, communication and Informatics 2, 10-13 (2018)

14. A. Zhuravlev, Vestnik Dnepropetrovskogo nacional'nogo universiteta zheleznodorozhnogo transtorta 1(61) (2016)

15. E. Shevtsova, S. Kudryavtsev, Soil Mech. and Found. Engin. 5(41), 177-184 (2004)

16. S. Kudryavtcev, V. Ulitskii, V. Paramonov, I. Sakharov, Soil mech. and found. Engin. Springer New York Consultants Bureau, ISSN: 0038-0741 (2015)

17. A. Edigaryan, S. Kvashuk, Earth Sciences 12, 146-151 (2017) 